\title{
Investigating the Impact of the Learning Context for Pre-service Teachers' Motivation
}

\author{
Barbara Otto \\ Goethe University; Ludwigsburg University of Education, \\ Frankfurt, Germany
}

\author{
Giang-Nguyen T. Nguyen \\ University of West Florida, Pensacola, USA
}

\begin{abstract}
This quantitative study investigated pre-service teachers' motivation in a teacher education program and was guided by the well-established framework of Self-Determination Theory (Deci \& Ryan, 1985). The study examined three research questions: (1) To what degree are German pre-service teachers motivated to learn in their teacher education program?; (2) Can their motivation be predicted by their perceived learning context?; and if so, (3) Is the perceived learning context still a significant predictor after controlling for participants' extroversion? 109 pre-service teachers enrolled at a German university voluntarily participated. Data were collected by a questionnaire assessing pre-service teachers' motivation to learn in their program, their perceived learning environment, as well as their extroversion. The analyses revealed that pre-service teachers are autonomously motivated, which considerably depends on the perceived learning context. Moreover, the perceived learning context is still a significant predictor of pre-service teachers' motivation after controlling for extroversion. The findings provide some practical implications suggesting how to instruct pre-service teachers at universities.
\end{abstract}

Keywords: teacher education, self-determination theory, intrinsic motivation, basic need satisfaction, learning environment

\section{Introduction}

Currently, approximately 912,000 teachers teach at German schools (Kultusministerkonferenz, 2014). Many are senior teachers who will be retired within the next few years. Thus, a teaching career attracts many graduating students faced with the question of which occupation to choose. Accordingly, for the academic year 2010-2011 about 55,000 students were expected to enroll in a teacher program at a German university (Informationssystem Studienwahl \& Arbeitsmarkt, 2013).

Surprisingly, despite myriad published research about motivation, only a few studies have addressed the question of the motivation of individuals entering the teaching field (Woolfolk Hoy, 2008). Most of those empirical studies investigated (pre-service) teachers' motivation by examining their motives or reasons for choosing the teaching profession (e.g., Watt \& Richardson, 2008). In Germany, the Potsdam Teacher Survey (Schaarschmidt, 2005) examined the main reasons why German pre-service teachers chose the teaching career. This empirical study revealed that more than half of the German pre-service teachers showed motivational

Barbara Otto, Ph.D., Department of Educational Psychology, Goethe University; Department of Psychology, Ludwigsburg University of Education.

Giang-Nguyen T. Nguyen, Ph.D., Department of Teacher Education and Educational Leadership, University of West Florida. 
deficits such as low ambition, low engagement, and low value of (educational) work. Watt and Richardson (2008) found similar results in Australia. They identified three types of beginning teachers: "highly engaged persisters", who wanted to pursue a lifetime career of teaching; "highly engaged switchers", who planned to only teach for a span and already contemplated other careers after "outgrowing" the teacher profession; and "lower engaged desisters", who seemed to be disappointed with teaching as a career choice. Parents would like their children to be taught by teachers who are "highly engaged persisters". However, only $46 \%$ of the surveyed teachers were identified as this kind. These results also mean that more than half of the respondents were not intrinsically motivated to consider teaching a lifetime career. These findings may suggest that the decision to become a teacher is only a stopgap for those who originally wished to pursue other career options. In this context, Watt and Richardson (2008) found a significantly higher motivation for teaching as a fallback career among highly engaged switchers and lower engaged desisters compared to highly engaged persisters. On the other hand, highly engaged persisters showed significantly higher levels of intrinsic motivation for teaching compared to the other two groups of pre-service teachers. Indeed, a range of empirical studies have revealed that both pre-service and novice teachers show a strong intrinsic motivation to teach (Chong \& Low, 2009; Guarino, Santibanez, \& Daley, 2006; Sinclair, 2008) and that the motivation for teaching is generally stable over the first five years of actual teaching in the classroom (Richardson \& Watt, 2010).

The requirements for entering a teacher career program at German universities have become stricter in the last few years. Therefore, the undesirable trends found by Schaarschmidt (2005) may have subsided by now. Given that subsequent studies on teacher motivation depict a high level of goal-orientation and certainty about career choice among German pre-service teachers and education students (e.g., Foerster, 2008; Rothland, 2010), one can assume that current German pre-service teachers are more likely to be highly engaged persisters and therefore are intrinsically motivated to study about teaching. However, to present time, little is known about pre-service teachers' motivation to learn in their program. As the teaching profession strives to attract and retain high quality teachers, it is worth delving further into aspects of teacher motivation, particularly the motivation of those enrolled in teacher education programs (Mansfield \& Beltman, 2014). This present study focused on investigating pre-service teachers' motivation for learning in their program.

Not only is there a dearth of research on pre-service teachers' motivation to learn, but previous research on this topic is missing a link to psychological theories and models of motivation (Watt \& Richardson, 2007). The current paper is guided by one of the most well established theoretical frameworks in the field of motivation, namely Self-Determination Theory (SDT) (Deci \& Ryan, 1985; Ryan \& Deci, 2000a, 2000b). SDT not only describes different degrees of motivation but also distinguishes between several types of motivation, such as different reasons or goals that give rise to an action (Ryan \& Deci, 2000a). Moreover, SDT presumes context to play a crucial role in the development of motivation. This paper will provide details concerning these two aspects of SDT.

\section{Theoretical Background}

\section{Types of Motivation}

In Self-Determination Theory (SDT), motivation is distinguished as intrinsic and/or extrinsic. In the educational domain intrinsic motivation to learn refers to those learning behaviors accomplished because they are considered to be interesting and enjoyable. Unfortunately, many aspects of education are not inherently interesting or enjoyable and will require extrinsic motivation (Niemiec \& Ryan, 2009). Students are 
extrinsically motivated to learn if they are driven by an expected outcome (external impetus) following their learning, such as receiving a reward or trying to avoid punishment (see Ryan \& Deci, 2000a).

The mere distinction between intrinsic and extrinsic motivation, however, is more complex than a simple separation between the two types of motivation. As SDT posits, there are various types of extrinsic motivation involved when thinking about students who are less interested in learning a subject: some students learn with resistance and disinterest, while others do so with an inner attitude of willingness (see Ryan \& Deci, 2000a). The latter case would reflect a somewhat internalized way to motivate oneself to learn. SDT presumes four distinct types of extrinsic motivation (see Figure 1) that vary with regard to the degree to which they are perceived to be autonomous (Niemiec \& Ryan, 2009) or self-determined.

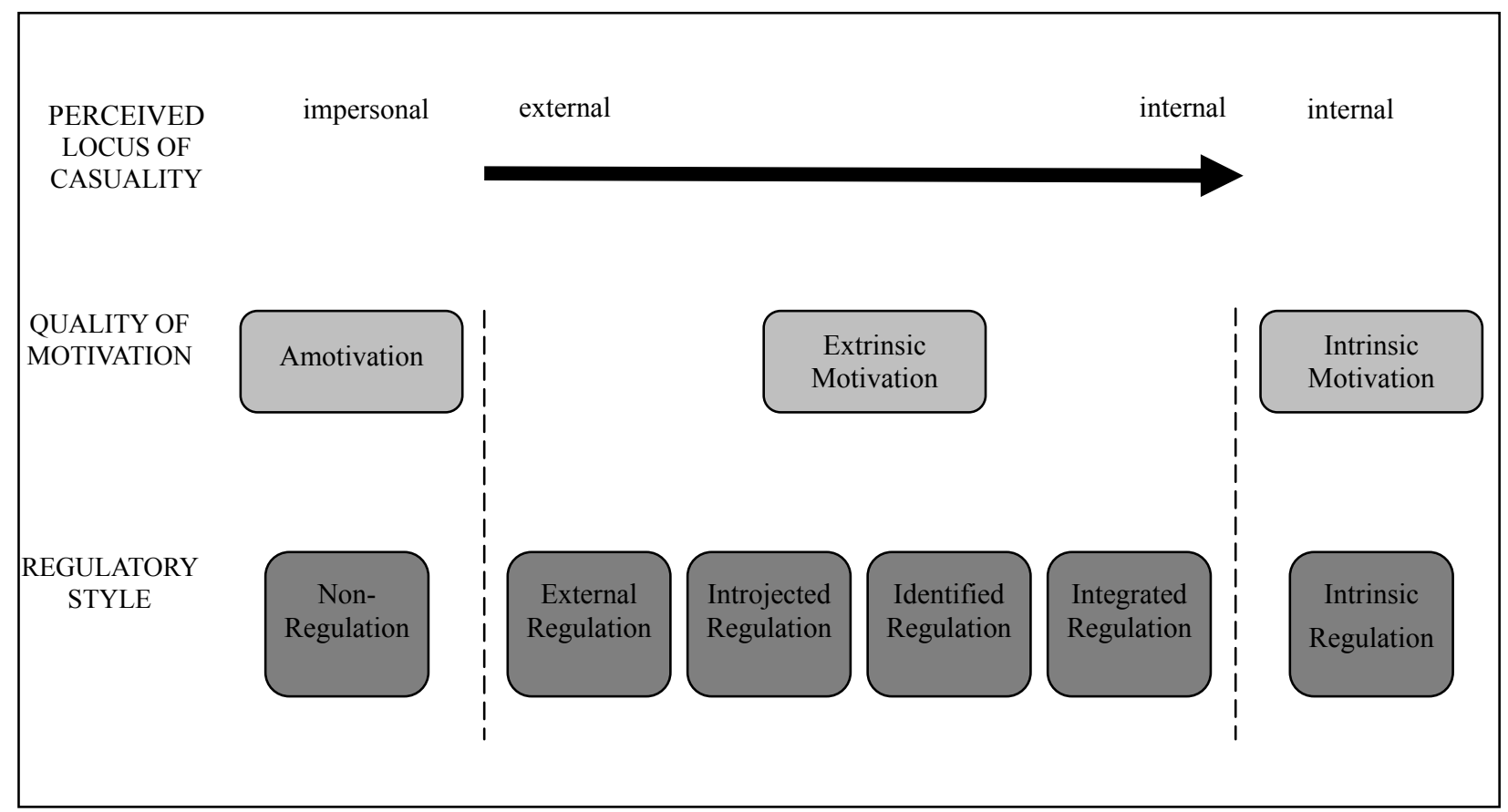

Figure 1. Types of motivation and associated regulatory styles posited by SDT (according to Ryan \&Deci, 2000b).

On the far left of Figure 1, the motivational state is called "amotivation". A student is amotivated when $\mathrm{s}(\mathrm{h}) \mathrm{e}$ lacks any intention to attempt to learn. To the right of "amotivation" is "extrinsic regulation", the least autonomous type of extrinsic motivation. In this state a student attempts to learn in order to satisfy an external demand or receive an externally imposed reward. It has been shown that extrinsically regulated behaviors are hardly maintained once the external, controlling consequences have been removed (Vansteenkiste, Ryan, \& Deci, 2008). The next category of extrinsic motivation is "introjected regulation". This state involves feeling pressure to avoid guilt or anxiety or to attain ego-enhancements or pride (Ryan \& Deci, 2000a). In other words, the main motivation for learning is to reduce internal pressure regarding a desire to feel proud or to avoid shame. A more self-determined form of extrinsic motivation is "regulation through identification". Here, a student has identified with the personal importance of a learning activity (Ryan \& Deci, 2000a). Specifically, the learning behavior is considered to be valuable or relevant for a life goal such as graduating from a university. The most autonomous category of extrinsic motivation is "integrated regulation". Actions characterized by integrated regulation are evaluated and brought into congruence with one's other values and 
needs and thus are assimilated (Ryan \& Deci, 2000b). Integrated regulations share many qualities with intrinsic motivation but are still extrinsic because the action is done for its supposed instrumental value and not for the behavior itself (Ryan \& Deci, 2000a).

Many empirical studies in the educational context reveal that more autonomous extrinsic motivation, namely identified and integrated regulation, is associated with higher engagement (Connell \& Wellborn, 1991), higher persistence (Ratelle, Guay, Vallerand, Larose, \& Senécal, 2007), higher performance (Guay, Ratelle, Roy, \& Litalien, 2010; Miserandino, 1996; Taylor, Jungert, Mageau, Schattke, Dedic, Rosenfield, \& Koestner, 2014, study 1), higher perceived competence and interest (e.g., Black \& Deci, 2000; Krapp, 2005), and lower dropout rates (Vallerand, Fortier, \& Guay, 1997). Thus, these would be the most desired types of extrinsic motivation for pre-service teachers.

At the far right of the continuum is the classic state of "intrinsic motivation" as the prototype of self-determination (Taylor et al., 2014). Here a student intrinsically regulates himself/herself by enjoying the specific task. In the context of the present study, the pre-service teacher would engage in learning because $s(\mathrm{~h}) \mathrm{e}$ is highly interested in the (educational) content of the teacher program. No other (external) reasons would have to be provided. It would be highly desirable to only have intrinsically motivated students in the teacher program. However, there is always less interesting content that also has to be learned. Thus, pre-service teachers will not incessantly be intrinsically motivated for all of their seminars and lectures. Therefore, it is to great advantage to facilitate self-determined learning situations in order to support autonomous extrinsic as well as intrinsic learning motivation.

\section{Basic Psychological Needs and the Role of Learning Environment}

The classic theories of motivation posit that motivation is always a function of internal (person) and external variables (context). Accordingly, in SDT three basic psychological needs (internal) are assumed which have to be satisfied by the social and environmental context (external) before more autonomous versions of motivation can emerge: the need for competence, the need for autonomy, and the need for relatedness (Ryan \& Niemiec, 2009).

Whenever students feel able to effectively master a class assignment, the "need for competence" is satisfied (Ratelle \& Duchesne, 2014). Instructors can facilitate their students' perceived competence by optimal challenges, freedom from demeaning evaluations (Ryan \& Deci, 2000a), and summative instead of formative feedback (Chan \& Lam, 2010). Realizing these conditions in teacher programs at universities would support pre-service teachers to experience the feeling of competence and thereby develop higher levels of autonomous motivations.

However, the mere feeling of being competent will not enhance intrinsic motivation unless it is accompanied by a sense of autonomy (Ryan \& Deci, 2000b). Learners must also experience their learning behavior as volitional and reflectively self-endorsed (Niemiec \& Ryan, 2009) in order to maintain or enhance more autonomous motivation. They have to feel independent from undesired internal or external pressure (Krapp, 2005). In this context, research has shown that autonomy-supportive teaching practices are associated with positive outcomes in the classroom (e.g., Chirkov \& Ryan, 2001; Jang, Reeve, Ryan, \& Kim, 2009; Tsai, Kunter, Lüdtke, Trautwein, \& Ryan, 2008; Sheldon \& Krieger, 2007; Vansteenkiste et al., 2012). Instructors can support the "feeling of autonomy" by giving the learner choices and the opportunity for self-direction. Any kind of perceived control (e.g., threats, deadlines, competition pressure) leads to a diminishing effect on 
intrinsic motivation. Thus, with regard to the quality of motivation to learn, pre-service teachers could benefit from a more autonomy-supportive instruction in their program.

Besides the perceived autonomy and competence, a third factor, namely the "need for relatedness", is crucial for intrinsic motivation. If students feel related to their teachers and experience a sense of security, an autonomous learning motivation can flourish. Low perceived relatedness leads to a decrease in autonomous motivation (den Brok, Brekelmans, \& Wubbels, 2004; Maulana, Opdenakker, \& Bosker, 2014; Opdenakker, Maulana, \& den Brok, 2012; Wubbels \& Brekelmans, 2005). Hence, pre-service teachers' learning motivation might also be enhanced by esteeming a positive learning context characterized by instructors who treat their pre-service teachers with respect and provide group projects with congenial fellow students in order to promote their perceived relatedness.

In summary, only people who experience themselves as competent, self-determined, and related to others in a supporting learning context will have the chance to develop intrinsic motivation to learn. Thus, in the teacher program at universities, pre-service teachers' intrinsic motivation requires the support of their needs for competence, autonomy, and relatedness, which can be provided by the social agents of the learning context (instructors).

\section{Research Questions}

In order to investigate German pre-service teachers' motivation and its conditions in the teacher education program three research questions were posed.

Research Question 1 (RQ1): Which types of motivation for learning predominate among pre-service teachers?

So far, most research studies completed in the field of education addressed the motivation of middle and high school students or university students of programs other than education. RQ 1 addresses the extent of the different types of motivation German pre-service teachers experience in their program.

Research Question 2 (RQ2): Does the perceived learning context account for the variability in pre-service teachers' intrinsic motivation to learn?

The mere examination of the degree and quality of pre-service teachers' motivation does not answer the more important questions for practice: which factors would be decisive for the development of motivation and how might pre-service teachers' motivation be facilitated? There is some evidence that the quality of the perceived learning environment positively influences the occupational commitment of pre-service teachers (e.g., Canrinus, Helms-Lorenz, Beijaard, Buitink, \& Hofman, 2012). Many empirical studies in the educational context have already highlighted the core role of the perceived learning environment for the development of intrinsic motivation as assumed by SDT (see Niemiec \& Ryan, 2009). However, there exists no research so far that examines whether these principles can be generalized to respondents enrolled in a teacher program. If the assumptions of SDT are also true for this target group, it follows that pre-service teachers' intrinsic motivation depends on their perceived learning environment. Thus, the second research question of the present study addresses the relevance of the basic psychological need satisfaction by the social learning context.

Research Question 3 (RQ3): Does the learning environment significantly predict pre-service teachers' intrinsic motivation even after controlling for their extroversion?

Other evidence demonstrates that intrinsically motivated behavior is associated with the personality of a person. Particularly for the university context the study of Komarraju, Karau, and Schmeck (2009) revealed the 
decisive role of the Big Five personality traits (neuroticism, extraversion, openness, agreeableness, and conscientiousness) in predicting college students' academic motivation and achievement. Also, the results of Clark and Schroth (2010) indicated that those who were intrinsically motivated to attend college tended to be extroverted, agreeable, conscientious, and open to new experiences. It can be assumed that this is also true for students enrolled in a teacher program.

In line with Decker and Rimm-Kaufman (2008), it is critically important to examine what personal attributes (e.g., personality) pre-service teachers have, as these may relate to their beliefs, their own learning (see Clark \& Schroth, 2010; Komarraju, Karau, \& Schmeck, 2009) and thus the way they teach their future students. In this context the question can be raised: Which is the decisive personality trait for a successful teacher? Research shows that teachers are required two essential qualities: first, being very sociable and, second, showing leadership qualities (see Goodstein \& Lanyon, 1999; Rockoff, Jacob, Kane, \& Staiger, 2008). Both attributes are combined in the personality trait extroversion. Empirical studies have not only revealed a significant correlation of extroversion with intrinsic motivation (e.g., Clark \& Schroth, 2010) but also indicated a significant relationship between students' reports of cognitive learning and teachers' self-reported extroversion. In contrast, teachers' neuroticism did not show significant correlations (e.g., Valencic, 2001). In a study by Khodadady and Mirjalili (2013), teachers' extroversion showed the highest correlation of all personality traits with student achievement. As these findings demonstrated the relevance of extroversion for the degree of interest and willingness in learning and teaching, the third research question focuses on the mediating role of pre-service teachers' extroversion.

\section{Methodology}

\section{Research Design}

The data were collected using a cross-sectional design during regular university class sessions. The participants were recruited by the researcher (first author) in five different seminars. Over $90 \%$ of the students agreed to voluntarily participate in the study. The respondents did not receive any benefits for participation.

\section{Participants}

Data were collected from 109 German students who were enrolled in the teacher program at a German university (mean age 23.1 years). $81 \%$ of the respondents were female. $7.3 \%$ were indicated to have no German citizenship. The participants graduated high school with a mean grade of 2.34 in the German grading system (equivalent with a B- in the U.S. grading system). They had already studied in the program for an average of 3.68 semesters $(S D=1.96)$.

The German education system is unique, as it tracks school-aged students depending on their academic performance. For the first four years (primary school), all students are taught together in one class (no tracking). With the beginning of middle school (grade 5), primary school teachers assign their students to one of three school tracks depending on their school performance: low-achievers are assigned to the lowest track (Hauptschule), average achievers to the middle track (Realschule), and high-achievers to the highest track (Gymnasium). Additionally, there exist schools of special education.

Of all participants, $29.4 \%$ were enrolled in the primary teacher education program, $21.1 \%$ studied in an education program for the lower tracks (Hauptschule and Realschule), and 27.5\% for the higher track (Gymnasium). The remaining students $(22.0 \%)$ were enrolled in the teacher program for special education. 
Before starting the teacher education program, $16.5 \%$ of all participants had finished a vocational training and $30.3 \%$ had begun to study in a different program, which only $3.7 \%$ graduated from.

\section{Instruments}

All participants completed a questionnaire, which assessed pre-service teachers' motivation to learn for their program as well as their perceived learning environment at the university. The questionnaire consisted of a translated version of the Self-Regulation Questionnaire in Academic Settings (SRQ-A; Ryan \& Connell, 1989) and assessed extrinsic motivation ( 9 items, $\alpha=0.72$ ), introjected motivation ( 9 items, $\alpha=0.74$ ), identified motivation ( 7 items, $\alpha=0.76$ ), and intrinsic motivation ( 7 items, $\alpha=0.82$ ). Due to the overlaps with intrinsic motivation, the SRQ-A does not assess integrated motivation separately. As the SRQ-A originally addresses learning in school as opposed to a program, the wording was adapted to the university context (e.g., "Why do I try to do well in school?" was changed to "Why do I try to do well in my program?").

The administered questionnaire also assessed students' perceived basic psychological need satisfaction (BPNS) by the learning environment (12 item, $\alpha=0.82$ ). These items were based on the Learning Climate Questionnaire (LCQ) (see also Black \& Deci, 2000) and were also translated into German. As the original items of the LCQ can be used for the university context, no adaptations in wording needed to be done. All translations of both original English questionnaires were done by a German researcher. Afterwards they were checked and corrected by a qualified bilingual interpreter. As an additional variable of the learning context, the overall satisfaction with the instruction was assessed by a German scale from Schwarzer and Jerusalem (1999; 3 items, $\alpha=0.76$; e.g., "The contents of the classes are usually interesting for us.").

In order to control for the core personality trait of interest in the present study, the scale extroversion (12 items, $\alpha=0.79$ ) from the German personality test NEO-FFI (Borkenau \& Ostendorf, 2008) was administered to the participants.

All items of the administered questionnaire could be answered on a five-point Likert scale ( $0=$ "I do not agree at all"; 1 = "I do not agree"; 2 = "I moderately agree"; 3 = "I agree"; 4 = "I totally agree").

\section{Results}

The collected data were analyzed by the statistical program SPSS 22.0. In case of any missing data those were listwise deleted.

\section{RQ1: Pre-Service Teachers' Quality and Degree of Motivation}

The first research question addressed the degree of different types of motivation to learn in the teacher education program. Figure 2 depicts the extent of the different motivational types of all participants. The respondents reported a relative high degree of autonomous motivation, namely intrinsic and identified regulation, whereas the degree of introjected and extrinsic regulation is lower. $T$-tests for paired samples showed that all four types of motivation significantly differed from one another $\left(T_{\text {intrinsic vs. identified }}=-12.17, p<\right.$ $0.001 ; T_{\text {intrinsic vs. introjected }}=5.48, p<0.001 ; T_{\text {intrinsic vs. extrinsic }}=11.14, p<0.001 ; T_{\text {identified vs. introjected }}=15.63, p<$ $\left.0.001 ; T_{\text {identified vs. extrinsic }}=18.89, p<0.001 ; T_{\text {introjectd vs. extrinsic }}=9.45, p<0.001\right)$. These results indicate that the respondents perceive a relative high level of self-determination while studying in their program.

\section{RQ2: Learning Environment as Predictor of Pre-Service Teachers' Motivation}

At initial analysis, the intercorrelation between both assumed relevant environmental factors was checked: the correlation analysis revealed a medium but highly significant association $(r=0.34 ; p<0.001)$ between 
respondents' perceived basic needs satisfaction and overall satisfaction with the instruction. Despite this significant correlation, both of the predictors only share about $11 \%$ common variance. Thus, they were both considered as complementing contextual factors and included separately into the subsequent Multiple Regression Analyses.

As expected, the first Multiple Regression Analysis showed that both predictors of the learning environment accounted for $32 \%$ of the variance in the criterion: perceived basic need satisfaction (Beta $=0.208$, $T=2.43 ; p<0.05)$ as well as students' overall satisfaction with the instruction $($ Beta $=0.462, T=5.38 ; p<$ 0.001 ) significantly predicted students' intrinsic motivation to learn for their program. Thus, pre-service teachers develop a higher intrinsic motivation the more they perceive a satisfaction of their basic psychological needs for autonomy, competence, and relatedness, and the more satisfied they are with the instructional design of the classes in their program.

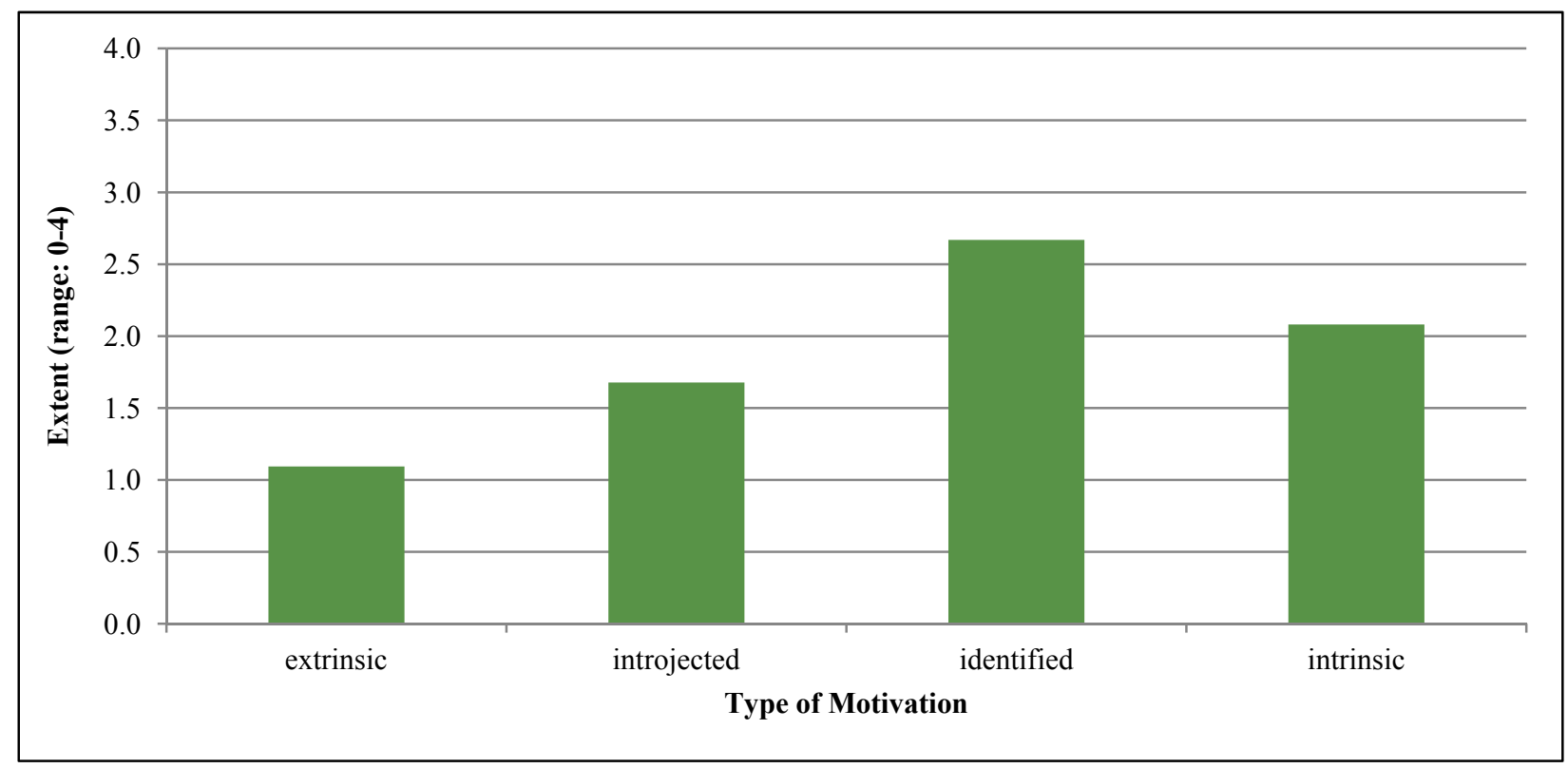

Figure 2. Mean extent of different types of motivation.

\section{RQ3: Potential Mediation by Extraversion}

In a second step, we examined whether results of the former Multiple Regression Analysis could be confirmed even after controlling for extroversion as core variable of a teacher's personality. A Blockwise Multiple Regression Analysis was conducted with the NEO-FFI scale extroversion (personality) in the first block and both of the learning environment scales in the second block. The findings are shown in Table 1. The results of the analysis revealed that the first model (extroversion) marginally predicts pre-service teachers' intrinsic motivation ( $p=0.08$ ), accounting for only $3 \%$ of the variance in the dependent variable. This pure result would suggest if a pre-service teacher shows a high level of extroversion (s)he also tends to be intrinsically motivated for learning in the teacher program. However, adding the predictors of the learning environment (model 2) leads to a reduction of this marginal influence of extroversion (Beta $=0.069 ; T=0.83 ; p$ $=0.41)$. In contrast, the results of model 2 again reveal a highly significant prediction $\left(R^{2}=34 \%\right)$ of respondents' intrinsic motivation by their perceived learning context. Thus, perceived basic psychological need satisfaction and respondents' overall satisfaction with the instruction could significantly account for pre-service 
teachers' intrinsic motivation and added $31 \%$ of explained variance to the prediction. This value is nearly as high as considering only the learning environment without the personality trait (RQ2).

Table 1

Blockwise Regression Analyses to Predict Intrinsic Motivation

\begin{tabular}{llllllllll}
\hline Model & Predictor & Beta & $T$ & $p$ & $R$ & $R^{2}$ & $\Delta R^{2}$ & $\Delta F(d f)$ & $\Delta p$ \\
\hline Model 1 & Extroversion (NEO-FFI) & 0.172 & 1.75 & 0.08 & 0.17 & 0.03 & 0.03 & $3.06(1,100) 0.08$ \\
Model 2 & Extroversion (NEO-FFI) & 0.069 & 0.83 & 0.41 & 0.59 & 0.34 & 0.31 & $23.27(2,98) 0.00$ \\
& Basic need satisfaction & 0.229 & 2.63 & 0.01 & & & & \\
& Overall satisfaction with instruction & 0.449 & 5.11 & 0.00 & & & & \\
\hline
\end{tabular}

\section{Discussion and Limitations}

The basic research questions in this present study examined motivation of German pre-service teachers. In particular, the study examined two aspects: (a) the extent of pre-service teachers' motivation to learn in the teacher education program; and (b) whether or not intrinsic motivation can be predicted by the perceived learning environment at the university. Responding to Watt and Richardson's (2007) assertion that research on teacher motivation is missing a link to psychological theories and models, this study is based on the well-established Self-Determination Theory (Deci \& Ryan, 1985) as a vehicle to explore pre-service teachers' motivation and the influencing contextual factors.

\section{RQ1: Pre-Service Teachers' Quality and Degree of Motivation}

Descriptive analyses revealed that respondents who are enrolled in a German teacher education program are autonomously motivated for their learning: on average, the degree of students' intrinsic and identified regulation was significantly higher than the degree of students' introjected and extrinsic regulation. These findings are consistent with recent empirical studies on teacher motivation (e.g., Pohlmann \& Möller, 2010; Watt \& Richardson, 2007) which found that pre-service teachers reported higher intrinsic than extrinsic motivation with regard to their field of study. However, as this study assessed data of pre-service teachers who were already enrolled in the teacher program for an average of almost two years, there might have been a self-selection in the first semesters, which would not be accounted for. Those pre-service teachers who were not autonomously motivated might have already dropped out of the program. Therefore, the present study may have only included pre-service teachers who were still enrolled (and answered the questionnaire) and were more interested in teaching. However, a recent report of Heublein, Richter, Schmelzer, and Sommer (2012) indicated a quite low dropout rate (about 6\%) of students enrolled in a German teacher education program. Therefore, the present findings can be assumed to be quite reliable. Despite this low dropout rate, future studies should focus on student teachers at their entrance into the program in order to control for any kind of self-selection. These students could be re-assessed regularly with a longitudinal design in order to examine the development of their motivation and performance (e.g., Malmberg, 2008; Watt \& Richardson, 2008).

The influence of self-selection is even more relevant when looking at the findings of the studies of Watt and Richardson (2008), who revealed that about half of the pre-service teachers were less motivated to teach as their lifetime career. These findings allow further discussions and implications for researchers and practitioners. First, such findings call for more effort in developing and testing reliable as well as valid instruments which enable assessment of professional suitability and abilities of pre-service teacher students (Rauin, 2008) in order to prevent high dropout rates during the program or during the professional careers. Such instruments could 
assess various types of motivation as realized in the present study. It might also be instructive to include different personality traits (e.g., conscientiousness) as well as other relevant factors with regard to teachers' professionalism, such as domain-specific knowledge, teachers' beliefs, and their self-regulatory competence (see also Kunter et al., 2007). In Germany, such assessment tools currently do not exist and thus more research must be done with regard to this topic.

\section{RQ2: Learning Environment as Predictor of Pre-Service Teachers' Motivation}

The second research question of this study hypothesized that the perceived learning environment would play a core role in pre-service teachers' intrinsic motivation. As expected, the findings confirmed the assumption of SDT concerning the high relevance of the contextual factors for intrinsic motivation of pre-service teachers: Not only was students' perceived basic psychological need satisfaction a significant predictor, but also their overall satisfaction with the instruction. These two factors accounted for $32 \%$ of pre-service teachers' intrinsic motivation to learn. Typically, only the three basic psychological needs are assessed as predictors for motivation. Therefore, it might be beneficial to pay close attention to the overall satisfaction scale. Why is this scale such a strong predictor for intrinsic motivation? One potential reason might be that the respondents "sum up" all of their experiences and perceptions with the instruction when answering the questions about their overall satisfaction. This might be an additional but less differentiating indicator for basic psychological need satisfaction. The above mentioned significant correlation also supports this. However, in order to investigate this assumption more precisely a longitudinal design should be employed in future studies.

With regard to the core role of the learning context for intrinsic motivation, it might also be useful to better understand the experiences and aspirations of pre-service teachers who report low motivation. It might be possible to enhance their interest by improving the nature of their education. According to Self-Determination Theory (Deci \& Ryan, 1985, 2000; see also Niemiec \& Ryan, 2009) these less motivated teacher students might, for instance, benefit by more formative rather than summative feedback (see Chan \& Lam, 2010) from their instructors, more choices in the tasks they are supposed to complete or the contents they are supposed to learn, less competitive learning situations, group projects, and an atmosphere characterized by friendliness and less hierarchical structures. The effects of such changes in the learning context might be examined by an intervention study particularly addressing pre-service teachers at risk to drop out of the teacher education program.

\section{RQ3: Potential Mediation by Extraversion}

Concerning the third research question, the Blockwise Multiple Regression Analysis revealed that the internal personality factor, namely pre-service teachers' extroversion, only had a marginal impact on respondents' intrinsic motivation. These findings may support the aforementioned research of Clark and Schroth (2010) revealing that extroversion shows a positive association with intrinsic motivation. However, when adding the context variables in the Blockwise Regression Analysis (model 2) the marginal impact of extroversion diminished, indicating a rather minor role of this personality trait for pre-service teachers' motivation.

Unfortunately, in the present study only one personality trait was assessed, which was hypothesized to potentially be essential for pre-service teachers' motivation to learn in their program. In future studies it might be beneficial to consider the other four of the Big Five personality traits: conscientiousness, neuroticism, 
openness, and agreeableness (see McCrae \& Costa, 2004) and examine which impact those factors have for pre-service teachers' motivation when simultaneously considering the context variables.

\section{Limitations}

One basic limitation of the present study is associated with the rather small sample of respondents that voluntarily took part in our measurements and thus were not randomized. Moreover, the data were collected from a quite heterogeneous sample, which differed not only in teacher programs (e.g., primary and secondary school teacher programs), but also in the chosen subjects and the semesters they had already studied. Thus, the present findings are constricted and may not necessarily be generalizable. Particularly with respect to the first research question about the degree of different types of motivation experienced with learning for the program, the present analyses can only provide a preliminary indication of the answer. Answering this research question with such a small sample size would usually demand comparative data from, for example, other study programs, other countries, or experienced teachers. Therefore, in future studies, similar data should either be collected with a larger sample size or with a comparative sample.

Methodologically, it must be acknowledged that the chosen research design, a cross-sectional approach, holds some limitations. In future studies, a longitudinal design should be utilized in order to explore how the perceived learning context and students' individual factors (e.g., personality) influence the "development" of intrinsic motivation and internalization. It would be interesting to examine whether the same predictive patterns exist during a longer trial period. After identifying the core contextual predictors, these could be investigated by an intervention study to show in which way an optimized learning environment affects the degree and development of autonomous motivation in students of a teacher program at universities. Moreover, it might be beneficial for future studies to consider multiple measures of performance, such as grades, attained credit points per semester, time needed to finish the program, or other related motivational aspects such as the degree of commitment and the tendency to drop out. From this, the influence of the educational context on students' performance as well as the potential mediation by students' motivation could be further investigated.

\section{Conclusions and Practical Implications}

The findings of the present study underline the relevance of SDT (Deci \& Ryan, 1985) for the educational context of university teacher programs and also point to possibilities of how practitioners can face the challenging task of fostering more versus less intrinsic motivation in their students. Supporting intrinsic motivation is supposed to be one of the grand aims in education - a "natural wellspring of learning and achievement" (Ryan \& Deci, 2000a, p. 55), because the underlying intrinsic motivational tendencies of pre-service teachers can be seen to be a resource that could be harnessed by educators as they guide learning and development (Niemiec \& Ryan, 2009; Samuelowicz \& Bain, 2001). However, many of the educational activities prescribed at universities in teacher programs are not designed to be intrinsically interesting (see also Ryan \& Deci, 2000a). Thus, it is of great interest to know how instructors in teacher programs can foster the process of internalization and integration. The more learners' basic psychological needs are satisfied, the higher the chances that students will become more autonomously engaged in their studies (Niemiec \& Ryan, 2009). Therefore, in this final section we would like to provide some general recommendations referring to how to meet pre-service teachers' basic psychological needs with teacher programs at universities. 


\section{How to Enhance Pre-Service Teachers Perceived Autonomy}

With regard to the enhancement of perceived autonomy, instructors may minimize any control and pressure (e.g., evaluative procedures, high competition, threats, deadlines) while maximizing students' participation in decisions with regard to academic activities (e.g., topics, learning material, presentation) in order to enhance their students' intrinsic motivation and outcomes (see also Chirkov \& Ryan, 2001). This might also be accomplished by designing seminars with alternative teaching methods that enable students to become active learners rather than passive participants. In particular, emphasizing the meaningful rationale for why a specific learning activity is useful might also support pre-service teachers' perceived autonomy (e.g., Deci, Eghrari, Patrick, \& Leone, 1994; Reeve, Jang, Hardre, \& Omura, 2002). With regard to (less activating) lectures, this seems to be an appropriate way to support students' internalization.

\section{How to Facilitate Pre-Service Teachers' Perceived Competence}

Aiming at the facilitation of perceived competence, instructors at universities could also provide tasks for the students that optimally fit their abilities but still allow them to expand their competencies (see Niemiec \& Ryan, 2009). Even though in many countries regular evaluations and assessments of students are formally prescribed to be conducted, these summative evaluations should always be combined with formative and effectiveness - promoting feedback to provide information on how to master a specific task (Ryan \& Deci, 2000a).

\section{How to Foster Pre-Service Teachers' Perceived Relatedness}

With regard to fostering students' perceived relatedness in classrooms, it is suggested that internalization is more likely when students feel accepted and respected by not only their instructors but also by their peers. Thus, instructors in teacher programs should always treat their students with respect and as equal partners in the learning context. Implementing learning tasks in the classroom which require collaboration among students might also enhance students' feeling of being related. This idea has been supported by a growing number of studies showing that collaboration among classmates not only fosters students' motivation but also their performance, as they have to take greater responsibly for the learning outcome (e.g., Ginsburg-Block, Rohrbeck, \& Fantuzzo, 2006; Rohrbeck, Ginsburg-Block, Fantuzzo, \& Miller, 2003).

\section{Potential Long Term Effects}

Overall, as teachers' motivation has been shown to be associated with students' motivation, learning behavior, and perceptions of instructional practices (see e.g., Assor, Kaplan, Kanat-Maymon, \& Roth, 2005; Butler \& Shibaz, 2008) teachers' motivation should definitely be put more into the centre of attention of research. Many empirical studies have revealed that if teachers themselves experience pressure in their professional context they tend to use more controlling instructional strategies (Pelletier, Séguin-Lévesque, \& Legault, 2002), which in turn have an impact on students' motivation and engagement (Roth, Assor, Kanat-Maymon, \& Kaplan, 2007). If pre-service teachers themselves learn in a context featuring high autonomy-support, competence-support, and relatedness, these experiences may have a positive influence on their future students' motivation and learning. Accordingly, teacher programs should be designed to satisfy pre-service teachers' needs of autonomy, competence, and relatedness in order to support the development of their intrinsic motivation as well as their willingness to engage in less interesting tasks (Niemiec \& Ryan, 2009). This will enable them to become autonomy-supportive teachers in the future. 


\section{References}

Assor, A., Kaplan, H., Kanat-Maymon, Y., \& Roth, G. (2005). Directly controlling teacher behaviors as predictors of poor motivation and engagement in girls and boys: The role of anger and anxiety. Learning and Instruction, 15, 397-413.

Black, A. E., \& Deci, E. L. (2000). The effects of instructors' autonomy support and students' autonomous motivation on learning organic chemistry: A self-determination theory perspective. Science Education, 84, 740-756.

Borkenau, P., \& Ostendorf, F. (2008). NEO-FFI. Göttingen: Hogrefe.

Butler, R., \& Shibaz, L. (2008). Achievement goals for teaching as predictors of students' perceptions of instructional practices and students' help seeking and cheating. Learning and Instruction, 18, 453-467.

Canrinus, E. T., Helms-Lorenz, M., Beijaard, D., Buitink, J., \& Hofman, W. H. A. (2012). Self-efficacy, job satisfaction, motivation and commitment: Exploring the relationships between indicators of teachers' professional identity. European Journal of Psychology of Education, 27, 115-132.

Chan, J. C. Y., \& Lam, S. (2010). Effects of different evaluative feedback on students' self-efficacy in learning. Instructional Science, 38, 37-58.

Chirkov, V. I., \& Ryan, R. M. (2001). Parent and teacher autonomy-support in Russian and U.S. adolescents: Common effects on well-being and academic motivation. Journal of Cross-Cultural Psychology, 32, 618-635.

Chong, S., \& Low, E. (2009). Why I want to teach and how I feel about teaching: Formation of teacher identity from pre-service to the beginning teacher phase. Educational Research for Policy and Practice, 8(1), 59-72.

Clark, M. H., \& Schroth, C. A. (2010). Examining relationships between academic motivation and personality among college students. Learning and Individual Differences, 20(1), 19-24.

Connell, J. P., \& Wellborn, J. G. (1991). Competence, autonomy, and relatedness: A motivational analysis of self-esteem processes. In M. R. Gunnar, \& L. A. Sroufe (Eds.), Minnesota Symposium on Child Psychology (Vol. 22, pp. 43-77), Hillsdale, NJ: Erlbaum.

den Brok, P., Brekelmans, M., \& Wubbels, T. (2004). Interpersonal teacher behaviour and student outcomes. School Effectiveness and School Improvement, 15, 407-442.

Deci, E. L., Eghrari, H., Patrick, B. C., \& Leone, D. R. (1994). Facilitating internalization: The self-determination theory perspective. Journal of Personality, 62, 119-142.

Deci, E. L., \& Ryan, R. M. (1985). Intrinsic motivation and self-determination in human behavior. New York: Plenum.

Decker, L. E., \& Rimm-Kaufman, S. E. (2008). Personality characteristics and teacher beliefs among pre-service teachers. Teacher Education Quarterly, 35, 45-64.

Foerster, F. (2008). Personale Voraussetzungen von Grundschullehramtsstudierenden. Eine Untersuchung zur prognostischen Relevanz von Persönlichkeitsmerkmalen für den Studien- und Berufserfolg (Personal preconditions of pre-service primary school teachers: A survey regarding the prognostic relevance of personality for academic and professional success). Münster: Waxmann.

Ginsburg-Block, M., Rohrbeck, C., \& Fantuzzo, J. W. (2006). A meta-analytic review of social, self-concept, and behavioral outcomes of peer-assisted learning. Journal of Educational Psychology, 98(4), 732-749.

Goodstein, L. D., \& Lanyon, R. I. (1999). Applications of personality assessment to the workplace: A teview. Journal of Business and Psychology, 13(3), 291-322.

Guarino, C. M., Santibanez, L., \& Daley, G. A. (2006). Teacher recruitment and retention: A review of the recent empirical literature. Review of Educational Research, 76(2), 173-208.

Guay, F., Ratelle, C. F., Roy, A., \& Litalien, D. (2010). Academic self-concept, autonomous academic motivation, and academic achievement: Mediating and additive effects. Learning and Individual Differences, 20(6), 644-653.

Heublein, U., Richter, J., Schmelzer, R., \& Sommer, D. (2012). Die Entwicklung der Schwund- und Studienabbruchquoten an den deutschen Hochschulen (The development of the drop-out at German universities). Retrieved from http://www.his.de/pdf/pub_fh/fh-201203.pdf

Informationssystem Studienwahl \& Arbeitsmarkt. (2013). Lehramt/Schule-Der Teilarbeitsmarkt Schule in Deutschland (Teacher/School-The part-time job market in Germany). Retrieved from http://www.uni-due.de/isa/ta_schule/schule_frm.htm

Jang, H., Reeve, J., Ryan, R. M., \& Kim, A. (2009). Can self-determination theory explain what underlies the productive, satisfying learning experiences of collectivistically oriented Korean students?. Journal of Educational Psychology, 101, 644-661.

Khodadady, E., \& Mirjalili, P. (2013). Foreign language achievement and its relation to teacher effectiveness and personality. Journal of Studies in Social Sciences, 2, 191-210. 
Komarraju, M., Karau, S. J., \& Schmeck, R. R. (2009). Role of the Big Five personality traits in predicting college students' academic motivation and achievement. Learning and Individual Differences, 19(1), 47-52.

Kultusministerkonferenz. (2014). Schüler, Klassen, Lehrer und Absolventen der Schulen 2003 bis 2012 (Students, classes, teachers, and graduates of schools 2003 till 2012). Retrieved from http://www.kmk.org/fileadmin/pdf/Statistik/ Dokumentationen/SKL_Dok_2012.pdf

Kunter, M., Klusmann, U., Dubberke, T., Baumert, J., Blum, W., Brunner, M., Jordan, A., Krauss, S., Löwen, K., Neubrand, M., \& Tsai, Y.-M. (2007). Linking aspects of teacher competence to their instruction-Results from the COACTIV project. In M. Prenzel (Ed.), Studies on the educational quality of schools (pp. 39-59). Münster: Waxmann.

Krapp, A. (2005). Basic needs and the development of interest and intrinsic motivational orientations. Learning and Instruction, $15,381-395$.

Malmberg, L.-E. (2008). Student teachers' achievement goal orientations during teacher studies: Antecedents, correlates and outcomes. Learning and Instruction, 18, 438-452.

Mansfield, C. F., \& Beltman, S. (2014). Teacher motivation from a goal content perspective: Beginning teachers' goals for teaching. International Journal of Educational Research, 65, 54-64.

Maulana, R., Opdenakker, M.-C., \& Bosker, R. (2014). Teacher-student interpersonal relationships do change and affect academic motivation: A multilevel growth curve modelling. British Journal of Educational Psychology, 84(3), 459-482.

McCrae, R. R., \& Costa, P. T. (2004). A contemplated revision of the NEO Five-Factor Inventory. Personality and Individual Differences, 36(3), 587-596.

Miserandino, M. (1996). Children who do well in school: Individual difference in perceived competence and autonomy in above-average children. Journal of Educational Psychology, 88, 203-214.

Niemiec, C. P., \& Ryan, R. M. (2009). Autonomy, competence, and relatedness in the classroom: Applying self-determination theory to educational practice. Theory and Research in Education, 7, 133-144.

Opdenakker, M.-C., Maulana, R., \& den Brok, P. (2012). Teacher-student interpersonal relationships and academic motivation within one school year: Developmental changes and linkage. School Effectiveness and School Improvement, 23, 95-119.

Pelletier, L. G., Séguin-Lévesque, C., \& Legault, L. (2002). Pressure from above and pressure from below as determinants of teachers' motivation and teaching behaviors. Journal of Educational Psychology, 94, 186-196.

Pohlmann, B., \& Möller, J. (2010). Fragebogen zur Erfassung der Motivation für die Wahl des Lehramtsstudiums (FEMOLA). (Motivation for Choosing Teacher Education Questionnaire (FEMOLA)). Zeitschrift für Pädagogische Psychologie, 24, 73-84.

Ratelle, C. F., \& Duchesne, S. (2014). Trajectories of psychological need satisfaction from early to late adolescence as a predictor of adjustment in school. Contemporary Educational Psychology, 39(4), 388-400.

Ratelle, C. F., Guay, F., Vallerand, R. J., Larose, S., \& Senécal, C. (2007). Autonomous, controlled, and a motivated types of academic motivation: A person-oriented analysis. Journal of Educational Psychology, 99(4), 734-746.

Rauin, U. (2008). Studierverhalten und Eignung für den Lehrberuf_-Kann man riskante Karrieren prognostizieren? (Studying behaviour and suitability to be a professional teacher-Can risky careers be predicted?). Schulverwaltung NRW, 11, 313-316.

Reeve, J., Jang, H., Hardre, P., \& Omura, M. (2002). Providing a rationale in an autonomy-supportive way as a strategy to motivate others during an uninteresting activity. Motivation and Emotion, 26, 183-207.

Richardson, P. W., \& Watt, H. M. G. (2010). Current and future directions in teacher motivation research. In T. C. Urdan, \& S. A. Karabenick. (Eds.), The decade ahead: Applications and contexts of motivation and achievement; Advances in motivation and achievement (pp. 139-173). Bingley, UK: Emerald.

Rohrbeck, C. A., Ginsburg-Block, M. D., Fantuzzo, J. W., \& Miller, T. R. (2003). Peer-assisted learning interventions with elementary school students: A meta-analytic review. Journal of Educational Psychology, 95, 240-257.

Rockoff, J. E., Jacob, B. A., Kane, T. J., \& Staiger, D. O. (2008). Can you recognize an effective teacher when you recruit one? Retrieved from http://www.nber.org/papers/w14485

Roth, G., Assor, A., Kanat-Maymon, Y., \& Kaplan, H. (2007). Autonomous motivation for teaching: How self-determined teaching may lead to self-determined learning. Journal of Educational Psychology, 99, 761-774.

Roth, G., Assor, A., Kanat-Maymon, Y., \& Kaplan, H. (2008). Autonomous motivation for teaching: How self-determined teaching may lead to self-determined learning. Journal of Educational Psychology, 99, 761-774.

Rothland, M. (2010). Berufsorientierung und-motivation in der konsekutiven Lehrerbildung: diffus, trügerisch und defizitär? (Vocational orientation and motivation in the consecutive teacher education: Diffuse, illusive, and insufficient?). Die Deutsche Schule, 102, 21-36. 
Ryan, R. M., \& Connell, J. P. (1989). Perceived locus of causality and internalization: Examining reasons for acting in two domains. Journal of Personality and Social Psychology, 57, 749-761.

Ryan, R. M., \& Deci, E. L. (2000a). Intrinsic and extrinsic motivations: Classic definitions and new directions. Contemporary Educational Psychology, 25, 54-67.

Ryan, R. M., \& Deci, E. L. (2000b). Self-Determination Theory and the facilitation of intrinsic motivation, social development, and well-being. American Psychologist, 55(1), 68-78.

Ryan, R. M., Stiller, J., \& Lynch, J. H. (1994). Representations of relationships to teachers, parents, and friends as predictors of academic motivation and self-esteem. Journal of Early Adolescence, 14, 226-249.

Ryan, R. M., \& Niemiec, C. P. (2009). Self-determination theory in schools of education-Can an empirically supported framework also be critical and liberating. Theory and Research in Education, 7, 263-272.

Samuelowicz, K., \& Bain, J. D. (2001). Revisiting academics' beliefs about teaching and learning. Higher Education, 41, 299-325.

Schaarschmidt, U. (2005). Potsdamer Lehrerstudie - ein erstes Fazit (Potsdam Teacher Survey_First Results). In U. Schaarschmidt (Ed.), Halbtagsjobber-Psychische Gesundheit im Lehrerberuf-Analyse eines veränderungsbedürftigen Zustandes (Part-time jobber-Psychological health in the teaching profession-Analysis of a state in need to change) (pp. 141-160). Weinheim: Beltz.

Schwarzer, R., \& Jerusalem, M. (Hrsg.). (1999). Skalen zur Erfassung von Lehrer- und Schülermerkmalen (Scales to assess teacher and student characteristics). Berlin: Freie Universität Berlin.

Sheldon, K. M., \& Krieger, L. S. (2007). Understanding the negative effects of legal education on law students: A longitudinal test of self-determination theory. Personality and Social Psychology Bulletin, 33, 883-897.

Sinclair, C. (2008). Initial and changing student teacher motivation and commitment to teaching. Asia-Pacific Journal of Teacher Education, 36(2), 79-104.

Taylor, G., Jungert, T., Mageau, G., Schattke, K., Dedic, H., Rosenfield, S., \& Koestner, R. (2013). A self-determination theory approach to predicting school achievement over time: The unique role of intrinsic motivation. Contemporary Educational Psychology, 39, 342-358.

Taylor, G., Jungert, T., Mageau, G., Schattke, K., Dedic, H., Rosenfield, S., \& Koestner, R. (2014). A self-determination theory approach to predicting school achievement over time: The unique role of intrinsic motivation. Contemporary Educational Psychology, 39, 342-358.

Tsai, Y., Kunter, M., Lüdtke, O., Trautwein, U., \& Ryan, R. M. (2008). What makes lessons interesting? The role of situational and individual factors in three school subjects. Journal of Educational Psychology, 100, 460-472.

Valencic, K. M. (2001). An investigation of teachers' temperament and students' perceptions of teachers' communication behavior and students' attitudes towards teachers (Dissertation at West Virginia University). Retrieved from https://eidr.wvu.edu/eidr/documentdata.eIDR?documentid=1949

Vallerand, R. J., Fortier, M. S., \& Guay, F. (1997). Self-determination and persistence in a real-life setting: Toward a motivational model of high school dropout. Journal of Personality and Social Psychology, 72, 1161-1176.

Vansteenkiste, M., Ryan, R. M., \& Deci, E. L. (2008). Self-determination theory and the explanatory role of psychological needs in human well-being. In L. Bruni, F. Comim, \& M. Pugno (Eds.), Capabilities and happiness (pp. 187-223). Oxford, UK: Oxford University Press.

Vansteenkiste, M., Sierens, E., Goossens, L., Soenens, B., Dochy, F., Mouratidis, A., Aelterman, N., Haerens, L., \& Beyers, W. (2012). Identifying configurations of perceived teacher autonomy support and structure: Associations with self-regulated learning, motivation and problem behavior. Learning and Instruction, 22(6), 431-439.

Watt, H. M. G., \& Richardson, P. W. (2007). Motivational factors influencing teaching as a career choice: Development and validation of the "FIT-Choice" Scale. Journal of Experimental Education, 75, 167-202.

Watt, H. M. G., \& Richardson, P. W. (2008). Motivations, perceptions, and aspirations concerning teaching as a career for different types of beginning teachers. Learning and Instruction, 18, 408-428.

Woolfolk Hoy, A. (2008). What motivates teachers? Important work on a complex question. Learning and Instruction, 18, 492-498.

Wubbels, T., \& Brekelmans, M. (2005). Two decades of research on teacher-student relationships in class. International Journal of Educational Research, 43, 6-24. 